MATEC Web of Conferences 51, 03002 (2016)

DOI: $10.1051 /$ matecconf/20165103002

(C) Owned by the authors, published by EDP Sciences, 2016

\title{
PEMFC Performance with Metal Bipolar Plates Depending on the Channel Dimension
}

\author{
Kuikam Kwon ${ }^{1}$, Doogon $\mathrm{Kim}^{1}$, Yun Sik Kang ${ }^{2}$, Sang Moon Kim ${ }^{1}$, Sung Jong Yoo ${ }^{2}$, and Chong Nam \\ $\mathrm{Chu}^{1, \mathrm{a}}$ \\ ${ }^{1}$ Department of Mechanical and Aerospace engineering, Seoul National University, Seoul, Korea \\ ${ }^{2}$ Fuel Cell Research Centre, Korea Institute of Science Technology (KIST), Seoul 136-791, Republic or Korea
}

\begin{abstract}
Bipolar plates of a proton exchange membrane fuel cell (PEMFC) play an important role in removing liquid phase water as a by-product in order to facilitate the reaction between fuel and oxygen. A great amount of effort has been made to improve the performance of a fuel cell such as maximum current density or maximum power, by improving water removability of a bipolar plate. Most of the studies, however, are conducted numerically because of the complexity of analysing gas and liquid and the poor manufacturability of graphite bipolar plates. In this proceeding, we demonstrate that the performance of a PEMFC with metal bipolar plates can be enhanced by reducing the dimension of the channel. Bipolar plates were machined with stainless steel (type 316L) to have three different channel size $(1000 \mu \mathrm{m}, 500$ $\mu \mathrm{m}$ and $300 \mu \mathrm{m})$ and the performance of each assembled cells were tested. As a result, the maximum power density and the maximum current density increased by $25 \%$.
\end{abstract}

\section{Introduction}

A polymer exchange membrane fuel cell (PEMFC) is gaining significant attention in the various industry such as vehicle manufacturers, as eco-friendliness is becoming more and more important value nowadays. [1] A PEMFC emits pure water after converting electricity using hydrogen as a fuel, which is a representative merit to be nominated as a "green" energy device in the future. Accordingly, a great effort has been putting to develop related technologies for advanced PEMFCs worldwide. While a huge advance has been made in the boundary of academia, it still remains in question whether PEMFCs can be successfully commercialized, due to the high barrier of overall cost arising from expensive materials, complex manufacturing process, etc.

In order to meet the criteria to commercialize PEMFC, the cost of each part composing a cell should be minimized as much as possible while maintaining the overall performance. One of the effective ways is to replace the material of bipolar plates with economical conductive materials, i.e., commercial metals. [2] Graphite has been widely used as a common material for bipolar plates in the laboratory scale; however, graphite for manufacturing bipolar plates in the mass production basis is not affordable due to the high cost of the material itself, as well as the high cost of machining flow channels. Therefore, a great number of studies have been reported to increase performance of fuel cell

\footnotetext{
${ }^{\mathrm{a}}$ Corresponding author : cnchu@snu.ac.kr; chu7147@gmail.com
} 
with metal bipolar plates fabricated with commercial materials such as stainless steel, copper alloys, etc.

There are several theoretical reports with computational results, arguing that the performance of a PEMFC with metal bipolar plates can be maximized by diminishing the dimension of flow channel below sub-millimetre scale; yet few experiments has been conducted to demonstrate and verify such result. [3-6] In case of using commercial metals for fabricating bipolar plates, it is inevitable to accompany overall performance decrease compared to using advanced carbon-based materials. One of the methods to minimize the decrement in the performance is to optimize the design of flow channels on the bipolar plates. While a number of studies reports that reducing flow channels below submillimetre scale can be a useful way to maximize fuel cell performance in a given condition, most of the studies mainly rely on theoretical simulation results due to the difficulty in machining small flow channels. Therefore, it is necessary to test the fuel cell performance having sub-millimetre-sized flow channels on metal bipolar plates in various conditions to support the preceding results arguing the effectiveness of smaller flow channels.

In this proceeding, we demonstrate that the performance of a PEMFC with stainless steel bipolar plates increases as the dimension of flow channel decreases.

\section{Experimental}

\subsection{Bipolar plate fabrication}

To investigate the relationship between the channel size of a bipolar plate and the performance of a cell, metal bipolar plates with different channel sizes were fabricated. For easy machinability and further study, we used bare metal for the bipolar plate. It is widely known that bare metals are easily corroded under the typical working condition of a PEMFC. Graphite bipolar plates are generally used for academic purpose because of its high corrosion resistance. In this study, however, we used bare metal not only for the manufacturability of small channels but also for the high potential in various commercial applications. For example, in portable PEMFCs which are used in automobiles, metal bipolar plates are widely chosen for high strength, low volume, easy manufacturability and low cost. AISI stainless steel (type 316L) was used for fabricating bipolar plates; it is widely used in studies for metal bipolar plates because of its high corrosion resistivity. The type of flow channel was chosen to be single serpentine type, which is known for having excellent performance among several flow field designs. Channel width, depth and rib width were designed to be equal. Bipolar plates having the channel size of $1000 \mu \mathrm{m}, 500 \mu \mathrm{m}, 300 \mu \mathrm{m}$ were fabricated and tested respectively. The activation area of the bipolar plate was $5 \mathrm{~cm}^{2}$.

\subsection{Performance test for a single cell}

A single cell with fabricated bipolar plate at cathode was assembled and activated by the current sweep-hold method with a commercial fuel cell test system (WonATech Co. Ltd., WFCTS 1.11) and the detail procedure can be found elsewhere. [7] Polarized test was performed by the current sweep method at a $10 \mathrm{~mA} / \mathrm{cm}^{2} \mathrm{~s}^{2}$ rate using the system mentioned above. While fully-humidified $\mathrm{H}_{2}(99 \%)$ was input to the anode at a flow rate of $150 \mathrm{ml} / \mathrm{min}$ at $70{ }^{\circ} \mathrm{C}$, fully-humidified air $(99.9 \%)$ as a fuel were input to the cathode at a rate of $800 \mathrm{ml} / \mathrm{min}$. For the test using $\mathrm{O}_{2}$ as a fuel, fully-humidified $\mathrm{O}_{2}$ $(99 \%)$ at a flow rate of $200 \mathrm{ml} / \mathrm{min}$ was input while supplying $\mathrm{H}_{2}$ at the same condition above. The uncertainty of maximum power density in the measurement system is under $3 \%$.

\section{Results and discussion}

\subsection{Fuel cell performance}


Figure 1 shows the polarization curves of the tested PEMFC. We observed that overall performance of the tested cells increases as the channel size decreases. As the channel size decreases, maximum current density increased from $1.052 \mathrm{~A} / \mathrm{cm}^{2}$ to $1.311 \mathrm{~A} / \mathrm{cm}^{2}$ and power density increased from 0.37 $\mathrm{W} / \mathrm{cm}^{2}$ to $0.463 \mathrm{~W} / \mathrm{cm}^{2}$. It is worth noting that the rise in the performance from the cell with the channel size of $300 \mu \mathrm{m}$ to that of $500 \mu \mathrm{m}$ is much larger than the rise from the cell with the channel size of $1000 \mu \mathrm{m}$ to that of $500 \mu \mathrm{m}$. In the cell with the channel size of $300 \mu \mathrm{m}$, a rapid voltage drop near the limit current density was monitored, which is further discussed below.
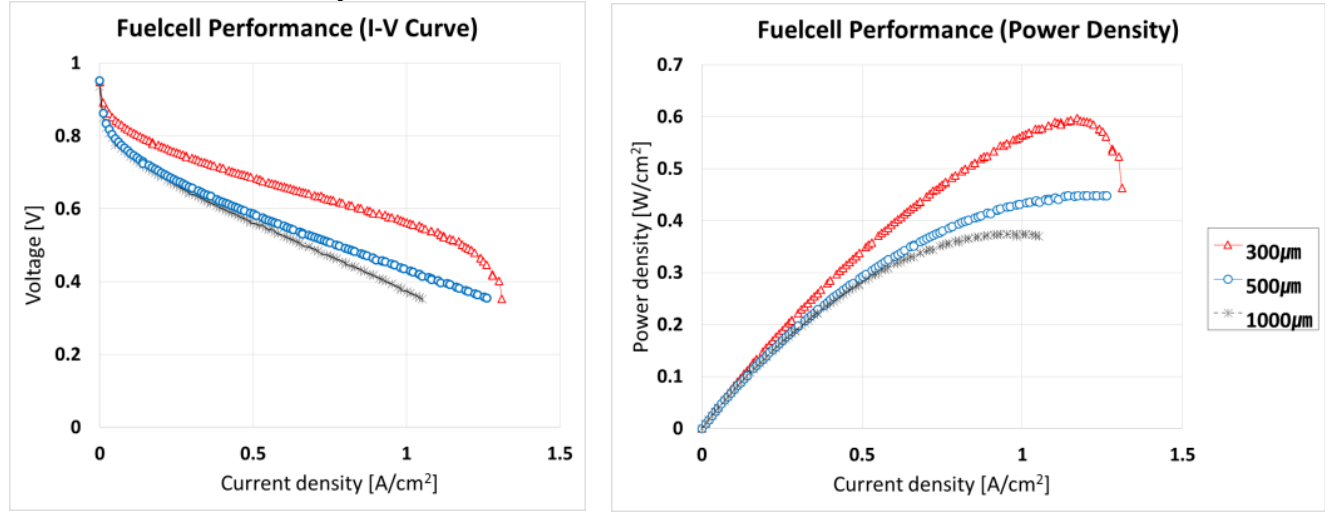

Figure 1. Polarization curves of tested PEMFC (a) I-V curve (b) Power density

\subsection{Discussion}

Some of the data does not match with the results in preceding numerical studies. [8] It was expected that overall performance tends to converge as the channel size decreases. In our results, however, the rise in the performance increases as the channel size becomes smaller. Further studies should be conducted to explain the difference between the result of preceding studies and our work.

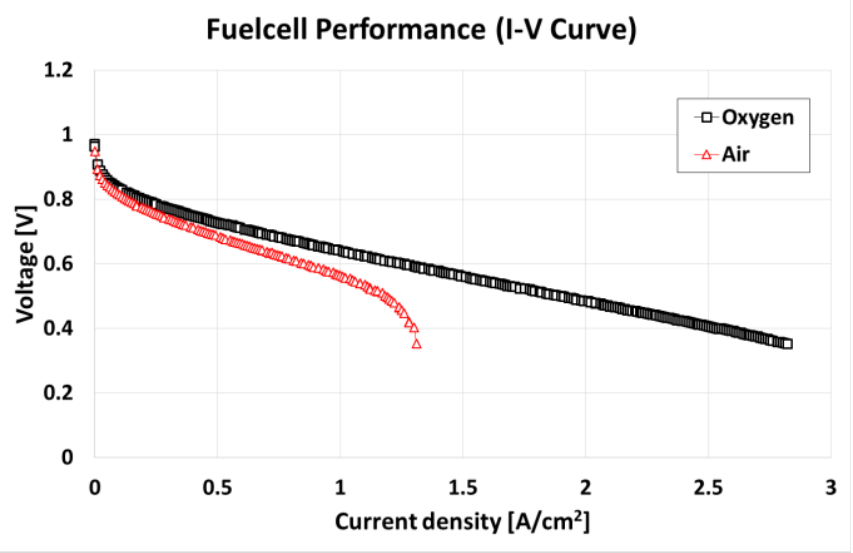

Figure 2. Performance comparison between different inlet gases

Also, In case of the channel size of $300 \mu \mathrm{m}$, performance abruptly drops near the limit current density, which was not observed in other cases. To check whether this unpredicted phenomenon occurs due to the water accumulation inside the channel, we changed the input gas from air to pure $\mathrm{O}_{2}$.

To prevent the performance change due to the total amount of input $\mathrm{O}_{2}$, pure $\mathrm{O}_{2}$ was inserted with $200 \mathrm{ml} / \mathrm{min}$ which was calculated to contain the same amount of $\mathrm{O}_{2}$ in case of $800 \mathrm{ml} / \mathrm{min}$ of air. As we can see in Figure 2, the overall performance improved without any sudden voltage drop. From this, 
we draw a conclusion that the rapid voltage drop is not due to the water accumulation because the total amount of produced water between the case of supplying air and $\mathrm{O}_{2}$ would be the same.

We assumed that the sudden voltage drop are due to the air pressure growth inside the flow channel which may cause an increase in the total amount of supplied $\mathrm{O}_{2}$ in the reaction site. We will further conduct the performance test with air at a lower flow rate so that we will be able to observed a stable performance of the cell with the channel size of $300 \mu \mathrm{m}$. Also, to generalize our results in other types of bipolar plates, additional test with different flow field designs will be conducted. Electrochemical impedance spectroscopy (EIS) analysis will be performed to investigate the major cause of overall performance improvement as the channel size decreases.

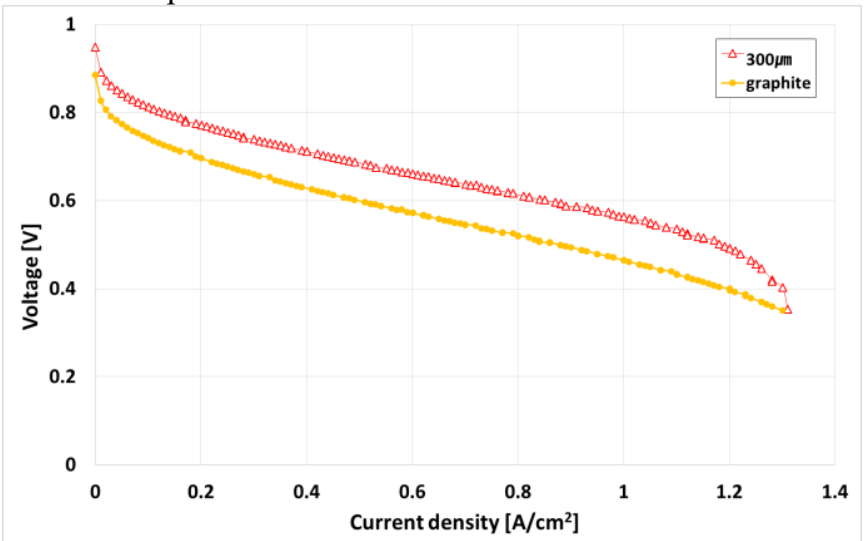

Figure 3. Performance comparison between original graphite bipolar plate and bipolar plate with $300 \mu \mathrm{m}$ channel

To see whether the performance of PEMFC with metal bipolar plate is comparable to that of PEMFC with graphite bipolar plate, performance of PEMFC with reference graphite bipolar plates is observed under same experimental condition. Reference graphite bipolar plate has same feature with the bipolar plate which has $1000 \mu \mathrm{m}$ channel. As you can see in Figure 3, overall performance of PEMFC with $300 \mu \mathrm{m}$ channel bipolar plate is comparable to the PEMFC with graphite bipolar plate. Based on this result, we verified that PEMFC with metal bipolar plates can be compatible with PEMFC with graphite bipolar plates.

\section{Conclusions}

By demonstrating the performance test of a PEMFC with metal bipolar plates, we conclude that reducing the dimension of the flow channel can be an effective way to minimize the performance deterioration of PEMFC due to the change of material of bipolar plates. We observed continuous increases in the limit current density and the power density as the channel dimension decrease from $1000 \mu \mathrm{m}$ to 500 and $300 \mu \mathrm{m}$, which supports preceding reports claiming the effectiveness of submillimetre-sized flow channels. Further study is to be performed in order to elucidate the sudden drop in the voltage plot by modulating the flow rate of supplied fuel.

\section{Acknowledgement}

This work was supported by the Brain Korea 21 Plus Project in 2015.

\section{References}

1. H. Tawfik, Y. Hung, D. Mahajan, J. Power Sources 163, 755-767 (2007)

2. S. Karimi, N Fraser, B. Roberts, F.R. Foulkes, Adv. Mater. Sci. Eng. 2012, 828070 (2012)

3. S. Shimpalee, J.W. Van Zee, Int. J. Hydrog. Energy 32, 842-856 (2007) 
4. E. Mancusi, E. Fontana, A. Augusto, U. Souza, S.M.A. Guelli, U. Souza, Int. J. Hydrog. Energy 39, 2261-2273 (2014)

5. J. Cui, Y. Fu, J. Bionic. Eng. 9, 99-109 (2012)

6. A. Aiyejina, M.K.S. Sastry, J. Fuel Cell Sci. Technol. 9 (2012)

7. J.W. Lim, Y.H. Cho, M.J. Ahn, D.Y.Chung, Y.H. Cho, H. Jung, Y.S. Kang, O. Kim, M.J. Lee, M. Kim, Y.E. Sung, J. Electrochem, Soc, 159(4), B378-B384 (2012)

8. X.D. Wang, W.M. Yan, Y.Y. Duan, F.B. Weng, G.B. Jung, C.Y. Lee, Energy Conv. Manag. 51, 959-968 (2010) 